\title{
The use of diagnostic imaging in low back or leg pain
}

\author{
Ayşegül Yaman, ${ }^{1}$ Yeşim Gökçe Kutsal, ${ }^{1}$ Sevilay Karahan ${ }^{2}$ \\ ${ }^{1}$ Department of Physical and Rehabilitation Medicine, Hacettepe University Medical School, Ankara, Turkey \\ ${ }^{2}$ Department of Biostatistics, Hacettepe University Medical School, Ankara, Turkey
}

Received: February 2016 Accepted: December 2016

\begin{abstract}
Objectives: The aim of this study is to evaluate the imaging method preferences of physicians working in different clinics and departments for the patients suffering from low back and/or leg pain.

Patients and methods: In this retrospective study, the radiological imaging types of 900 patients (301 males, 599 females; mean age $46.8 \pm 17.1$ years; range 2 to 89 years) with low back and/or radicular leg pain who were admitted for the first time to the Physical Medicine and Rehabilitation (PMR), Orthopedics and Traumatology (OT), and Neurosurgery (NS) clinics in our hospital between July 2013 and August 2014 were reviewed. Age, sex, and radiological methods applied were recorded. The correlation between radiological methods and differences in terms of age and sex and how the radiological method preferences differed according to the departments were evaluated.

Results: Of the patients, 22\%, 35\% and 34.7\% were evaluated without using any imaging methods in the OT, PMR, and NS outpatient clinics, respectively. A total of $32.7 \%, 48.7 \%$, and $8.7 \%$ of the patients were evaluated using lumbar X-ray in the OT, PMR, and NS outpatient clinics, respectively. A total of $19.3 \%, 11.7 \%$, and $54.3 \%$ of the patients were evaluated using the lumbar magnetic resonance imaging (MRI) in the OT, PMR, and NS outpatient clinics, respectively. There were no statistically significant correlations between the age, sex, and imaging modality used.

Conclusion: Our study results showed that the most common imaging tool which is used by the physicians in the PMR and OT clinics is lumbar X-ray, while the lumbar MRI is the most common tool in the NS clinics. However, we recommend that not only the medical, but ethical aspects and cost-effectiveness of the imaging modality to be selected should be considered.
\end{abstract}

Keywords: Diagnostic imaging; low back pain; radiological imaging.

Low back pain has an enormous impact on individuals, families, communities, governments, and businesses throughout the world. ${ }^{[1]}$ More than $84 \%$ of adults have had back pain a few times throughout their lives. ${ }^{[2]}$ In 2010, $1.3 \%$ of admissions to clinics in the United States were due to back pain complaints. ${ }^{[3]}$

Up to $\% 90$ of patients with back pain have a mechanical reason for their pain. Low back pain is seen in all cultures and ethnic groups. The lifetime prevalence of low back pain varies between 59 and $80 \%$ in developed countries. ${ }^{[4]}$ Risk factors include heavy physical strain, vibration, obesity, and smoking. ${ }^{[4]}$

In a study conducted by Hoy et al..$^{[5]}$ in 2012 , the prevalence of back pain causing limitation of activities more than one day has been estimated as $12 \%$, while the prevalence of back pain lasting for one month was found to be $23 \%{ }^{[5]}$
While there are several causes for back pain, most of the patients have non-specific back pain. Symptoms improve rapidly in more than $90 \%$ of the patients with back pain. In terms of positive prognosis, unless there is potential high systematic etiology or neurological findings, radiological imaging is unnecessary within the first four to six weeks. ${ }^{[6]}$

The Clinical Efficacy Assessment Subcommittee of the American College of Physicians, American College of Physicians, and American Pain Society Low Back Pain Guidelines Panel do not recommend using routine imaging and other diagnostic tests for patients with non-specific back pain..$^{[7]}$

In a review and meta-analysis published in 2009, immediate imaging (magnetic resonance imaging [MRI], computed tomography [CT], and radiography) and routine therapy were compared in patients suffering from subacute and acute back pain who

Corresponding author: Ayşegül Yaman, MD. Hacettepe Üniversitesi Tıp Fakültesi Fiziksel Tıp ve Rehabilitasyon Anabilim Dalı, 06100 Sihhiye, Ankara, Turkey. e-mail: aysegulyaman06@gmail.com 
did not have any signs and symptoms of infection and malignancy, and no significant difference between long- (six to 12 months) or short-term (up to three months) pain and functional outcomes was found. ${ }^{[8]}$ In addition, abnormal findings are frequently detected in the imaging scans of adults who do not have back pain. ${ }^{[9]}$

Complaints about back pain is a frequent clinical phenomenon which can be seen in several age groups. Complaints can be eradicated by means of conservative approaches in a limited time period, and imaging methods do not have any apparent effect on the clinical results. The application of "red flag" criteria is recommended in several guidelines recently, which provides a more rational approach to the utilization of imaging methods. A great number of back pain cases are likely to heal after six to eight weeks of initial pain without any medical treatment. ${ }^{[6,10,11]}$ Therefore, X-ray is not recommended, unless the clinician does not suspect that back pain is caused by a problem such as spondylolisthesis or fracture.

Radiological examinations which are conducted without clinical history, physical examination findings of patients or without considering other clinical factors and used as the only source for decision making may cause both diagnostic complexities or confusions and waste of time and valuable resources.

In Turkey, patients with low back pain are referred to different departments. In our study, we aimed to evaluate the imaging method preferences of physicians working in different clinics and departments for the patients suffering from low back and/or leg pain.

\section{PATIENTS AND METHODS}

In this retrospective study, we reviewed radiological imaging types of a total of 900 patients (301 males, 599 females; mean age $46.8 \pm 17.1$ years; range 2 to 89 years) with low back and/or radicular leg pain who were admitted for the first time to the Physical Medicine and
Rehabilitation (PMR), Orthopedics and Traumatology (OT), and Neurosurgery (NS) clinics in our university hospital. All patients including 300 in each department were initially diagnosed and recorded to the electronic system as low back pain, lumbosacral root disorders, lumbago, or lumbar spondylosis. No exclusion criteria were applied for the study recruitment.

Age, sex, and radiological methods applied were recorded. The correlation between radiological methods and differences in terms of age and sex and how the radiological method preferences differed according to the departments were evaluated.

The study protocol was approved by the Hacettepe University Non-interventional Clinical Researches Ethics Committee. A written informed consent was obtained from each patient. The study was conducted in accordance with the principles of the Declaration of Helsinki.

\section{Statistical analysis}

The effect size was obtained as 0.57 in this study with 900 patients to analyze the differences of imaging methods among the three clinics. Accordingly, power of the study was found to be $100 \%$. Statistical analysis was performed using the IBM SPSS version 21.0 software (IBM Corp., Armonk, NY, USA). Descriptive data were presented in mean \pm standard deviation (SD), and median (min-max) values. Categorical variables were evaluated using the chi-square and Fisher's exact tests and expressed in number and percent. One-way analysis of variance (ANOVA) was used to determine the difference between the imaging methods according to age. A $p$ value of $<0.05$ was considered statistically significant.

\section{RESULTS}

The mean ages of the patients who applied to OT, PMR, and NS outpatient clinics were $45.8 \pm 19.4$ years, $47.3 \pm 15.7$ years, and $47.2 \pm 15.9$ years, respectively.

Table 1. The demographic characteristics of the patients

\begin{tabular}{|c|c|c|c|c|c|c|c|c|c|}
\hline & \multicolumn{2}{|c|}{ All patients $(n=900)$} & \multicolumn{2}{|c|}{$\operatorname{PMR}(\mathrm{n}=300)$} & \multicolumn{2}{|c|}{ OT $(n=300)$} & \multicolumn{2}{|c|}{ NS $(n=300)$} & \multirow[b]{2}{*}{$p$} \\
\hline & $\mathrm{n}$ & Mean \pm SD & $\mathrm{n}$ & Mean \pm SD & $\mathrm{n}$ & Mean \pm SD & $\mathrm{n}$ & Mean \pm SD & \\
\hline Age (year) & & $46.8 \pm 17.1$ & & $47.3 \pm 15.7$ & & $45.8 \pm 19.4$ & & $47.2 \pm 15.9$ & 0.449 \\
\hline Gender & & & & & & & & & 0.192 \\
\hline Female & 599 & & 200 & & 210 & & 189 & & \\
\hline Male & 301 & & 101 & & 90 & & 111 & & \\
\hline Age groups & & & & & & & & & $<0.001$ \\
\hline$<18$ & 38 & & 1 & & 29 & & 8 & & \\
\hline $18-50$ & 712 & & 185 & & 138 & & 160 & & \\
\hline$>50$ & 150 & & 114 & & 133 & & 132 & & \\
\hline
\end{tabular}

SD: Standard deviation; PMR: Physical Medicine and Rehabilitation; OT: Orthopedics and Traumatology; NS: Neurosurgery. 
Table 2. The imaging method used by the physicians from different clinics

\begin{tabular}{|c|c|c|c|c|c|c|c|c|c|}
\hline & \multicolumn{2}{|c|}{ All patients $(\mathrm{n}=900)$} & \multicolumn{2}{|c|}{$\operatorname{PMR}(\mathrm{n}=300)$} & \multicolumn{2}{|c|}{ OT $(n=300)$} & \multicolumn{2}{|c|}{ NS $(n=300)$} & \multirow[b]{2}{*}{$p$} \\
\hline & $\mathrm{n}$ & $\%$ & $\mathrm{n}$ & $\%$ & $\mathrm{n}$ & $\%$ & $\mathrm{n}$ & $\%$ & \\
\hline Imaging method & & & & & & & & & $<0.001$ \\
\hline Lumbar X-ray & 270 & 30 & 146 & 48.7 & 98 & 32.7 & 26 & 8.7 & \\
\hline Lumbar MRI & 256 & 28.4 & 35 & 11.7 & 58 & 19.3 & 163 & 54.3 & \\
\hline Lumbar X-ray and lumbar MRI & 28 & 3.1 & 4 & 1.3 & 20 & 6.7 & 4 & 1.3 & \\
\hline No imaging methods & 249 & 27.7 & 105 & 35 & 66 & 22 & 104 & 34.7 & \\
\hline $\begin{array}{l}\text { Other imaging methods } \\
\text { (Sacroiliac X-ray, hip X-ray, } \\
\text { pelvic X-ray, scoliosis X-ray, } \\
\text { thoracic X-ray, thoracic MRI, } \\
\text { lumbar plexus MRI etc.) }\end{array}$ & 97 & 10.8 & 10 & 3.3 & 58 & 19.3 & 3 & 1 & \\
\hline
\end{tabular}

In the OT clinics, total number of patients according to the age groups $<18,18$ to 50 , and $>50$ years were 29, 138, and 133, respectively. In the PMR clinics, total number of patients according to the age groups $<18,18$ to 50 , and $>50$ years were one, 185 , and 114 , respectively. In the NS clinics, total number of patients according to age groups $<18,18$ to 50 , and $>50$ years were eight, 160 , and 132 , respectively.

The demographic characteristics of the patients are shown in Table 1. There was no significant difference between the groups in terms of age and sex ( $>00.05)$. However, when the groups were divided according to age, we observed a significant difference among the three clinics $(\mathrm{p}<0.001)$ and the age group consisting of patients younger than 18 years in the OT.

Of the patients, $22 \%, 35 \%$ and $34.7 \%$ were evaluated without using any imaging methods in the OT, PMR, and NS clinics, respectively. A total of $32.7 \%$, $48.7 \%$, and $8.7 \%$ of the patients were evaluated using lumbar $\mathrm{X}$-ray in the OT, PMR, and NS clinics, respectively. A total of $19.3 \%, 11.7 \%$, and $54.3 \%$ of the patients were evaluated using the lumbar MRI in the OT, PMR, and NS clinics, respectively. The imaging methods preferred by the physicians in different clinics are summarized in Table 2. When the imaging tools were evaluated in all patients according to the clinics, lumbar X-ray was more used in the PMR and OT clinics, while lumbar MRI was more used in the NS clinics. The difference of imaging methods used among the clinics was statistically significant $(\mathrm{p}<0.001)$.

The demographic characteristics and imaging method used for the patients aged ranging between 18 to 50 years are shown in Table 3 . When all patients in the 18 to 50 age range were compared in terms of age and sex, there was no statistically significant difference among the clinics $(\mathrm{p}>0.05)$. However, lumbar X-ray was more used in the PMR and OT and lumbar MRI was more used in the NS clinics in the 18 to 50 age group.

There was no significant relationship between sex and imaging methods used. However, the patients who underwent imaging methods except for lumbar X-ray and/or lumbar MRI were younger than the others.

\section{DISCUSSION}

The necessity of imaging method depends on the patient's medical history and physical examination findings. ${ }^{[12]}$

In a study by Chou et al. ${ }^{[8]}$ applying an imaging method to the patients with back pain in the short-term (less than three months) and long-term (from six months up to one year) provided no advantage or contribution to the alleviation of pain and/or functional recovery.

In another study, the necessity of radiological imaging for patients with back pain was shown and it was reported that lateral view showed more findings than anteroposterior view, and lateral view was sufficient in the initial scanning for patients with back pain. ${ }^{[13]}$

Recently, there has been an increase in the utilization rate of MRI. ${ }^{[14]}$ In their study on the features of back pain in patients who required MRI, Jame et al. ${ }^{[15]}$ found that $46.7 \%$ had an indication for MRI, while $46.5 \%$ had no indication and $4.5 \%$ had both an indication and contraindication at the same time and $2.3 \%$ had a contraindication. In the aforementioned study, MRI was required by the clinicians, of whom $37 \%$ were neurologists, $33 \%$ orthopedists, $19 \%$ neurosurgeons, $2 \%$ PMR specialists, and $8 \%$ other major/specialties (i.e., emergency physicians, general surgeons, oncologists, and rheumatologists). A total of $88 \%$ of 


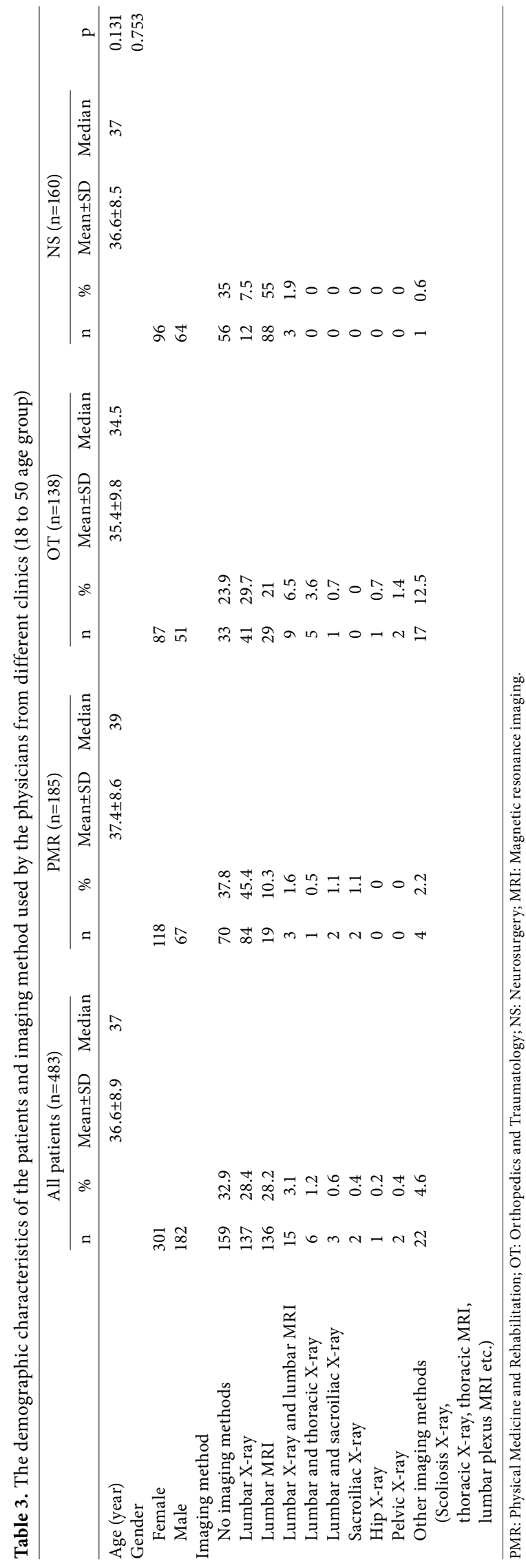

400 patients who required MRI were not consulted to a PMR physician, before they were referred to the imaging centers.

Lehnert and Bree ${ }^{[16]}$ demonstrated that $26 \%$ of the imaging studies were inappropriate, and in $35 \%$ of the patients with back pain, MRI was applied without any indication and without prior conservative therapy methods.

Similarly, in their study, Jame et al. ${ }^{[15]}$ showed that, in more than $70 \%$ of the patients, no therapy methods such as rest, medical treatment, and physical therapy were applied before the MRI evaluation.

If a patient experiences back pain only six to eight times a week; if he or she is treated with rest, light exercise or analgesic or anti-inflammatory medication and his or her condition is getting better or there is an increase in his or her activities, X-ray is not a must. Clinicians may not recommend another X-ray for those who do not have any significant structural causes related to the back pain, which lasts more than two years, unless there is a new injury or illness.

A plain radiograph or more advanced imaging techniques such as MRI/CT may be ordered in back pain associated with radiculopathy or spinal stenosis and back pain associated with progressive neurological deficits. However, there is a limited role of imaging in non-specific acute low back pain without the red flags, as the findings poorly correlate with symptoms. Red flags which should be kept in mind include fever, age $>50$ years, recent trauma history, pain at night or at rest, progressive motor or sensory deficit, saddle anesthesia, unexplained weight loss, history of cancer or strong suspicion of cancer, history of osteoporosis or chronic steroid use, and immunosuppression or failure to improve after six weeks of conservative therapy. ${ }^{[17]}$

Furthermore, applying of the American College of Physicians and American Pain Society recommendations on use of imaging may reduce overuse of imagining methods. Immediate imaging is recommended, when the patients with low back pain have major risk factors for malignancies (i.e., new-onset of low back pain with history of cancer, multiple risk factors for cancer, or strong clinical suspicion for cancer), for spinal infection (i.e., newonset of low back pain with fever and history of intravenous drug use or recent infection), for signs of the cauda equina syndrome (i.e., new urine retention, fecal incontinence, or saddle anesthesia), and severe neurological deficits (i.e., progressive motor weakness or motor deficits at multiple neurological levels). If 
the patients have mild risk factors for cancer, for vertebral compression fractures, for signs of ankylosing spondylitis, signs and symptoms of radiculopathy, and risk factors or symptoms of spinal stenosis, imaging can be postponed after an attempt of therapy. Imaging is not recommended, when no criteria for immediate imaging and back pain is improved or resolved after a month attempt of therapy. ${ }^{[7,18]}$

Although some authors advocate that conservative management is effective and radiological investigation is unnecessary, some tends to use radiography and even MRI in the initial assessment of low back pain. It seems there is no consensus on this issue. In our opinion, there are no strict rules about the necessity of imaging and treatment procedures for specific clinical scenarios. In those cases in which evidence is lacking or equivocal, expert opinion may supplement the available evidence to recommend imaging or treatment. ${ }^{[19]}$

The limitation of our study is that all data were collected via electronic system. Therefore, we were unable to evaluate the duration of pain and the imaging method previously applied and whether the patient was previously referred to an external center.

In conclusion, our study results showed that the most common imaging tool which is used by the physicians in the PMR and OT clinics is lumbar X-ray, while the lumbar MRI is the most common tool in the NS clinics. However, we recommend that not only the medical, but ethical aspects and cost-effectiveness of the imaging modality to be selected should be considered.

\section{Declaration of conflicting interests}

The authors declared no conflicts of interest with respect to the authorship and/or publication of this article.

\section{Funding}

The authors received no financial support for the research and/or authorship of this article.

\section{REFERENCES}

1. Hoy D, Brooks P, Blyth F, Buchbinder R. The Epidemiology of low back pain. Best Pract Res Clin Rheumatol 2010;24:769-81.

2. Cassidy JD, Carroll LJ, Côté P. The Saskatchewan health and back pain survey. The prevalence of low back pain and related disability in Saskatchewan adults. Spine (Phila $\mathrm{Pa}$ 1976) 1998;23:1860-6.

3. Centers for Disease Control and Prevention. National Ambulatory Medical Care Survey: 2010 Summary Tables. Available from: http://www.cdc.gov/nchs/data/ ahcd/namcs_summary/2010_namcs_web_tables.pdf.
[Accessed on: September 30, 2014]

4. Erçalık C, Tuncer T. Epidemiology of mechanical low back pain. Turkiye Klinikleri J PM\&R-Special Topics 2011;4:1-5.

5. Hoy D, Bain C, Williams G, March L, Brooks P, Blyth F, et al. A systematic review of the global prevalence of low back pain. Arthritis Rheum 2012;64:2028-37.

6. van Tulder M, Becker A, Bekkering T, Breen A, del Real MT, Hutchinson A, et al. Chapter 3. European guidelines for the management of acute nonspecific low back pain in primary care. Eur Spine J 2006;15:169-91.

7. Chou R, Qaseem A, Snow V, Casey D, Cross JT Jr, Shekelle $\mathrm{P}$, et al. Diagnosis and treatment of low back pain: a joint clinical practice guideline from the American College of Physicians and the American Pain Society. Ann Intern Med 2007;147:478-91.

8. Chou R, Fu R, Carrino JA, Deyo RA. Imaging strategies for low-back pain: systematic review and meta-analysis. Lancet 2009;373:463-72.

9. Jensen MC, Brant-Zawadzki MN, Obuchowski N, Modic MT, Malkasian D, Ross JS. Magnetic resonance imaging of the lumbar spine in people without back pain. N Engl J Med 1994;331:69-73.

10. Bradley WG. ACR Appropriateness Criteria Low Back Pain. AJNR Am J Neuroradiol 2007;28:990-2.

11. Motiei-Langroudi R, Sadeghian H, Seddighi AS. Clinical and magnetic resonance imaging factors which may predict the need for surgery in lumbar disc herniation. Asian Spine J 2014;8:446-52.

12. Flynn TW, Smith B, Chou R. Appropriate use of diagnostic imaging in low back pain: a reminder that unnecessary imaging may do as much harm as good. J Orthop Sports Phys Ther 2011;41:838-46.

13. Atalabi OM, Ogunlade SO, Agunloye AM. The lumbosacral radiographs in the initial screening of low back pain - is one view enough? Niger J Clin Pract 2011;14:284-6.

14. Keshtkaran A, Bagheri MH, Ostovar R, Salari H, Farokhi MR, Esfandiari A, et al. Developing Criteria for Lumbar Spine Magnetic Resonance Imaging (MRI) Using RAND Appropriateness Method (RAM). Iran J Radiol 2012;9:130-8.

15. Jame SZ, Sari AA, Majdzadeh R, Rashidian A, Arab M, Rahmani H. The extent of inappropriate use of magnetic resonance imaging in low back pain and its contributory factors. Int J Prev Med 2014;5:1029-36.

16. Lehnert BE, Bree RL. Analysis of appropriateness of outpatient CT and MRI referred from primary care clinics at an academic medical center: how critical is the need for improved decision support? J Am Coll Radiol 2010;7:192-7.

17. Lateef $H$, Patel D. What is the role of imaging in acute low back pain? Curr Rev Musculoskelet Med 2009;2:69-73.

18. Chou R, Qaseem A, Owens DK, Shekelle P. Diagnostic imaging for low back pain: advice for high-value health care from the American College of Physicians. Ann Intern Med 2011;154:181-9.

19. Patel ND, Broderick DF, Burns J, Deshmukh TK, Fries IB, Harvey HB, et al. ACR Appropriateness Criteria Low Back Pain. J Am Coll Radiol 2016;13:1069-78. 